Jud, G. D. and D. T. Winkler. "Price Indexes for Commercial and Office Properties: An

Application of the Assessed Value Method to the Charlotte, NC Market," Journal of Real Estate

Portfolio Management, vol. 5, no. 1, 1999, pp: 71-81.

Made available courtesy of American Real Estate Society: http://www.aresnet.org/

***Reprinted with permission. No further reproduction is authorized without written permission from the American Real Estate Society. This version of the document is not the version of record. Figures and/or pictures may be missing from this format of the document.***

\title{
Price Indexes for Commercial and office Properties: An Application of the Assessed Value Method
}

Executive Summary. This study constructs a nonresidential, constant-quality price index, based on the assessed-value approach, and adjusts for the possibility for sample selection bias. The sample consists of a large sample of commercial and office properties located in Charlotte, N.C. during 1981-1994. Statistical tests for sample selection bias suggest that bias is present in the office sample, but not in the commercial property sample. For office properties, the selection process is such that higher prices prevail for equivalent office properties that sell relative to those that do not sell. The estimated price indexes indicate average appreciation rates of $16.2 \%$ for commercial property and $9.9 \%$ for office property.
*University of North Carolina-Greensboro, Greensboro, NC 27402-6165 or Juddon(a)uncg.edu.

** University of North Carolina-Greensboro, Greensboro, NC 27402-6165 or dt_winkler(a)uncg.edu. by G. Donald Jud*

Daniel T. Winkler**

\section{Introduction}

Understanding the pattern and direction of real estate price trends is important to investors, developers and other real estate market participants. Because real property is a heterogeneous commodity that trades infrequently, it is difficult to construct accurate measures of real estate price trends that properly adjust for quality changes over time.

A number of studies have estimated real estate price trends for single-family properties. ${ }^{1}$ Among recent work focusing on the methodological and empirical issues involved in the construction of residential price indexes are articles by Mark and Goldberg (1984), Case and Shiller (1989), Case and Quigley (1991), Case, Pollakowski and Wachter (1991), Abraham and Schauman (1991), Clapp and Giaccotto (1992), Hill, Knight and Sirmans (1997) and Knight, Dombrow and Sirmans (1995), among others. The high level of academic interest in this subject is attested by the dedication of two issues of the Journal of Real Estate Finance and Economics $(1997,14: 1,2)$ entirely to this topic. ${ }^{2}$

Haurin and Hendershott (1991) pointed out a troubling methodological issue that arises with this research. In their review of this literature, they raise the issue of a sample selection bias, where the sample of houses that sell and are used to develop a real estate price index may differ in some way from the stock of all houses. Thus, price indexes based on sales transactions may misrepresent 
price trends in the overall market. Jud and Seaks (1994) find empirical support for the existence of sample selection bias in a sample of residential sales in Charlotte, N.C. Gatzlaff and Haurin (1997, 1998), using data from Dade County Florida, also find evidence of selection bias and report that the magnitude of the bias is highly correlated with changes in economic conditions.

In contrast to the recent spate of work focusing on the single-family housing sector, the number of studies of price trends in other real estate sectors has been quite limited. The reason for the dearth of studies is primarily related to data availability. Methods such as the repeat sales method and the varying parameters approach (Knight, Dombrow and Sirmans, 1995) require large sample sizes. Despite data limitations, some progress in the development of real estate indices outside the singlefamily market has been made. Recent studies by Follain and Calhoun (1997) and Guttery and Sirmans $(1995,1998)$ have developed quality-adjusted indices for multi-family properties.

The problem of sample selection bias in a nonresidential price index is addressed by Webb, Miles and Guilkey (1992). They develop a model of commercial real estate values based on a national sample of commercial, office and industrial properties from 40 states during 1980-88, which was obtained from the National Council of Real Estate Investment Fiduciaries (NCREIF). The sample includes 592 properties, 270 of which were sold during the period and 322 which were unsold. Webb, Miles and Guilkey (WMG) estimate a hedonic price model using the observed prices from the 270 sold properties and test the model for sample selection bias. They find no evidence of sample selection bias. Using the predicted values from the estimated hedonic price model, WMG assign quarterly values to all properties in their sample and develop a nation-wide index of real estate returns for the 1980-88 period.

This article follows WMG in an attempt to develop a quality-adjusted price index for non-residential properties. The methodology employed here departs from the traditional hedonic approach used by WMG. Instead, it draws on the assessed-value method developed by Clapp and Giaccotto (1992).
This method uses tax appraisal data that are readily available in many jurisdictions across the country from local tax offices. Thus, the procedures outlined here can be easily replicated in different areas. Additionally, the methodology can be modified to adjust for sample selection bias, following the procedure used by Jud and Seeks (1994).

The next section describes the procedure for constructing the nonresidential, constant-quality price index. The methodology incorporates adjustment for possible sample selection bias. The following section discusses data collection procedures. The property sample is drawn from Mecklenburg County, N.C. (encompassing the city of Charlotte). The next section presents the constant-quality indexes for the commercial and offices sectors in Charlotte. The final section summarizes important findings and implications.

\section{Estimation of a Nonresidential Price Index}

The approach used here for estimating a constantquality index is the assessed value (AV) method first advanced by Clapp and Giaccotto (C\&G). This method relates the transaction price of the property to the assessed value of the property. Because it uses assessed value to estimate sales price, it imposes relatively modest demands for data, in contrast to the traditional hedonic approach that requires a rather large vector of property characteristics. The data are relatively easy to obtain, and the data have been checked and cleaned by government agencies. Moreover, the potential adjustment for sample selection bias is manageable when used in conjunction with a first-stage probit model.

The model employed by C\&G to estimate a real estate price index can be written as:

$$
\begin{aligned}
\ln P_{i t}= & \beta_{0}+\beta_{1} \ln \left(A_{i b}\right)+\delta_{1} Y 1_{i t} \\
& +\delta_{2} Y 2_{i t}+\ldots+\delta_{T} Y T_{i t}+\varepsilon_{i t}
\end{aligned}
$$

where, $P_{i t}=$ transaction price of the $i$ th commercial property at time $t,\left(i=1, \ldots, n_{t}\right.$, and $t=1$, $\ldots, T) ; A_{i b}=$ assessed value of property $i$ at time $b ; Y T_{i t}=$ a time dummy with values of 1 if the $i$ th 
commercial property sold in period $t$ and 0 otherwise; and $\varepsilon_{i t}=$ random error term. The regression coefficients $\delta_{1}, \delta_{2}, \ldots \delta_{T}$ represent the logarithm of the cumulative price index, and measure the price change in the respective periods. Although random errors in assessed value (measurement error) may pose a potential problem for the $\mathrm{AV}$ method, C\&G offer convincing evidence that measurement error bias goes to zero in large samples. ${ }^{3}$

A potential problem with most real estate price indexes is that they may suffer from sample selection bias. To deal with the sample selection problem, we follow Greene's (1993) exposition of the problem in assuming that there exists some latent selection variable $z^{*}$ that determines whether a property is sold during a particular time period. Generally, $z^{*}$ cannot be observed; rather, only the sign of $z^{*}$ can be inferred. If a property is sold, then $z^{*}$ is assumed to be positive and $z$ takes on the value 1 . If a property is not sold, then $z^{*}$ is zero or negative and we observe $z=0$. Thus, the probit model that governs the sale can be written as follows:

$$
\begin{aligned}
& z_{i t}^{*}=\gamma^{\prime} \mathbf{w}_{i t}+\mu_{i t}, \quad \mu_{i t} \text { is } N[0,1] \\
& z_{i t}^{*}=1 \text { if } z_{i t}^{*}>0, \\
& z_{i t}^{*}=0 \text { if } z_{i t}^{*} \leq 0, \\
& \operatorname{Prob}\left(z_{i t}=1\right)=\Phi\left(\gamma^{\prime} \mathbf{w}_{i t}\right), \\
& \operatorname{Prob}\left(z_{i t}=0\right)=1-\Phi\left(\gamma^{\prime} \mathbf{w}_{i t}\right),
\end{aligned}
$$

where $\Phi$ denotes the cumulative normal distribution. Because the likelihood of sale is not the same for homes at all price levels, $\mathbf{w}_{i t}$ denotes variables to capture the impact of local and national conditions on the probability of sale. These variables might include the log of the assessed tax value, the unemployment rate, the percentage change in building permits in the area, the mortgage interest rate and area location variables.

The AV model of real estate prices can be simplified and written as:

$$
p_{i t}=\boldsymbol{\beta}^{\prime} \mathbf{x}_{i t}+\varepsilon_{i t},
$$

where $\left(\mu_{i t}, \varepsilon_{i t}\right)$ are $N[0,0,1, \sigma, \rho]$ and $\rho$ is the correlation of $p$ and $z$. Haurin and Hendershott (1991) and Jud and Seaks (1994) emphasize that Equa- tion (3) is observed if $z=1$. Estimation of the coefficient vector $\boldsymbol{\beta}$ of Equation (3) without a correction for the sample selection bias will result in regression estimates that suffer from the equivalent of omitted variable bias. The net result is that estimates of $\beta$ will be biased and inconsistent if allowance is not made for the fact that the sample of properties that are sold may differ systematically from properties that are not sold.

If it is assumed that $z_{i t}$ and $\mathbf{w}_{i t}$ are observed for a random sample of properties, but $p_{i t}$ is observed only when $z_{i t}=1$, then the model can be written as:

$$
E\left[p_{i t} \mid z_{i t}=1\right]=\boldsymbol{\beta}^{\prime} \mathbf{x}_{i t}+\rho \sigma_{\varepsilon} \lambda\left(\boldsymbol{\gamma}^{\prime} \mathbf{w}_{i t}\right),
$$

where $\lambda\left(\gamma^{\prime} \mathbf{w}_{i t}\right)$ is the inverse Mills ratio given by $\phi\left(\gamma^{\prime} \mathbf{w}_{i t}\right) /\left[1-\Phi\left(\gamma^{\prime} \mathbf{w}_{i t}\right)\right]$ and $\phi$ and $\Phi$ denote the normal density and distribution functions, respectively. The presence of the variable $\lambda\left(\gamma^{\prime} \mathbf{w}_{i t}\right)$ in Equation (4) reveals the omitted variable bias that will result if Equation (3) is estimated from only the houses that are sold. This problem is confirmed by Jud and Seaks (1994) and Gatzlaff and Haurin $(1997,1998)$. If the estimated coefficient of $\lambda\left(\gamma^{\prime} \mathbf{w}_{i t}\right)$ is negative (positive), the expected price conditional upon sale is lower (higher) than the expected price conditional upon no sale.

Fortunately, consistent estimates of this equation can be obtained using Heckman's (1979) two-step procedure. In the first stage, a probit equation is estimated by maximum likelihood to obtain consistent estimates of $\gamma$. In the second stage, least squares regression is used to obtain consistent estimates of $\boldsymbol{\beta}$ and $\rho \sigma_{\varepsilon}^{2}$ by a regression of $p$ on $\mathbf{x}$ and $\lambda$.

\section{Data}

The database consists the Master Appraisal File of 66,951 commercial and office properties in Mecklenburg County, N.C. between 1980 and 1994. Of these properties, 2,228 were sold during the period. There were a total of 26,282 commercial properties with 606 sales and 40,669 office properties with 1,622 sales. The commercial sample included shopping centers and other retail establishments, 
excluding restaurants and fast food establishments. The office sample consisted of all office space properties, excluding medical buildings.

Exhibit 1 details descriptive statistics of the sample. The variables are defined as follows:

$$
\begin{aligned}
L P R I C E= & \text { Log of sales price; } \\
L T A X= & \text { Log of assessed tax value; } \\
U R= & \text { Unemployment rate in Mecklenberg } \\
& \text { County; } \\
P M T S= & \text { Percentage change in building per- } \\
& \text { mits in Mecklenberg County; } \\
M R A T E= & \text { Conventional mortgage rate in the na- } \\
& \text { tional market; } \\
D 11-D 14= & \text { Time dummy variables (equal } 1,0 \\
& \text { otherwise) for years 1981-1994; and } \\
A 1-A 7= & \text { Area dummy variables (equal 1, } 0 \\
& \text { otherwise) for Mecklenberg Co. } \\
& \text { municipalities. }
\end{aligned}
$$

The mean age of all properties is approximately 25 years of age. Using antilogs, the mean price of the commercial sample is $\$ 204,639$, compared with $\$ 147,266$ for offices. As shown by the time dummy variables, the number of sales per year is relatively uniform with the exception of 1994. The area dummy variables indicate about $87 \%$ of the sample consists of observations from the city of Charlotte $(A 1=1)$; the remaining municipalities each comprise about $2 \%$ or less of the total number of properties and the total number of sales.

The tax variable shows the assessed value of the property in 1991. Effort was made to eliminate properties that were materially altered between the appraisal date and the date of sale. Mecklenburg County tax assessors appraise all properties at fair market value. Revaluation must take place in North Carolina at least every eight years. In our sample, we use the appraised value as of 1991 , the most recent appraisal year. The tax office assigns individual appraisers to the appraisal of incomeproducing properties. Appraisers specialize in particular areas of the county and particular market segments (apartments, office buildings, etc.). Appraisers use the three traditional approaches to valuation in determining appraised values. During the appraisal process, property owners receive unofficial estimates of appraised value and are invited to present additional evidence if they disagree with the initial estimates. Owners of commercial property often provide income and expense estimates to county appraisers to support their estimates. If the property owners and the tax appraisers disagree on valuation, owners may appeal.

\section{Empirical Results}

The first stage uses a probit model to provide consistent estimates of $\gamma$. The probit model relates the dependent variable, whether a property is sold $\left(z_{i t}=1\right)$, to eleven independent variables. The eleven independent variables include the natural $\log$ of assessed value for property $i$ (LTAX), the local area unemployment rate in year $t(U R)$, the percentage change in building permits for the local area in year $t$ (PMTS), the national average mortgage rate (MRATE) and seven municipal-area dummy variables $(A 1 \ldots A 7)$. The $L T A X$ variable captures variation in the probability of sale associated with property value; the likelihood of sale may not be the same at different levels. The impact of national and local economic conditions is captured by the local unemployment rate, the percentage change in building permits and the national mortgage rate. It is expected that the probability of sale declines when the unemployment rate increases. Building activity as measured by PMTS is anticipated to be positively related to the probability of sale. The direction of MRATE, however, is less predictable. While it might be expected that higher interest rates decrease the probability of sale, MRATE may also capture economic activity, which is typically greater during periods of high interest rates. Because the probability of sale is likely to vary in different areas of the city, municipal area dummy variables are included in the model. The base of comparison is the area of Mecklenburg County outside a municipality.

Exhibit 2 shows the probit model results for commercial properties, office properties and the combined sample. ${ }^{5}$ The restricted log-likelihood ratio tests whether all eleven slopes are simultaneously equal to zero; in all three samples, the high $\chi^{2}$ values indicate statistical significance for all three 
Exhibit 1

Means and Standard Deviations

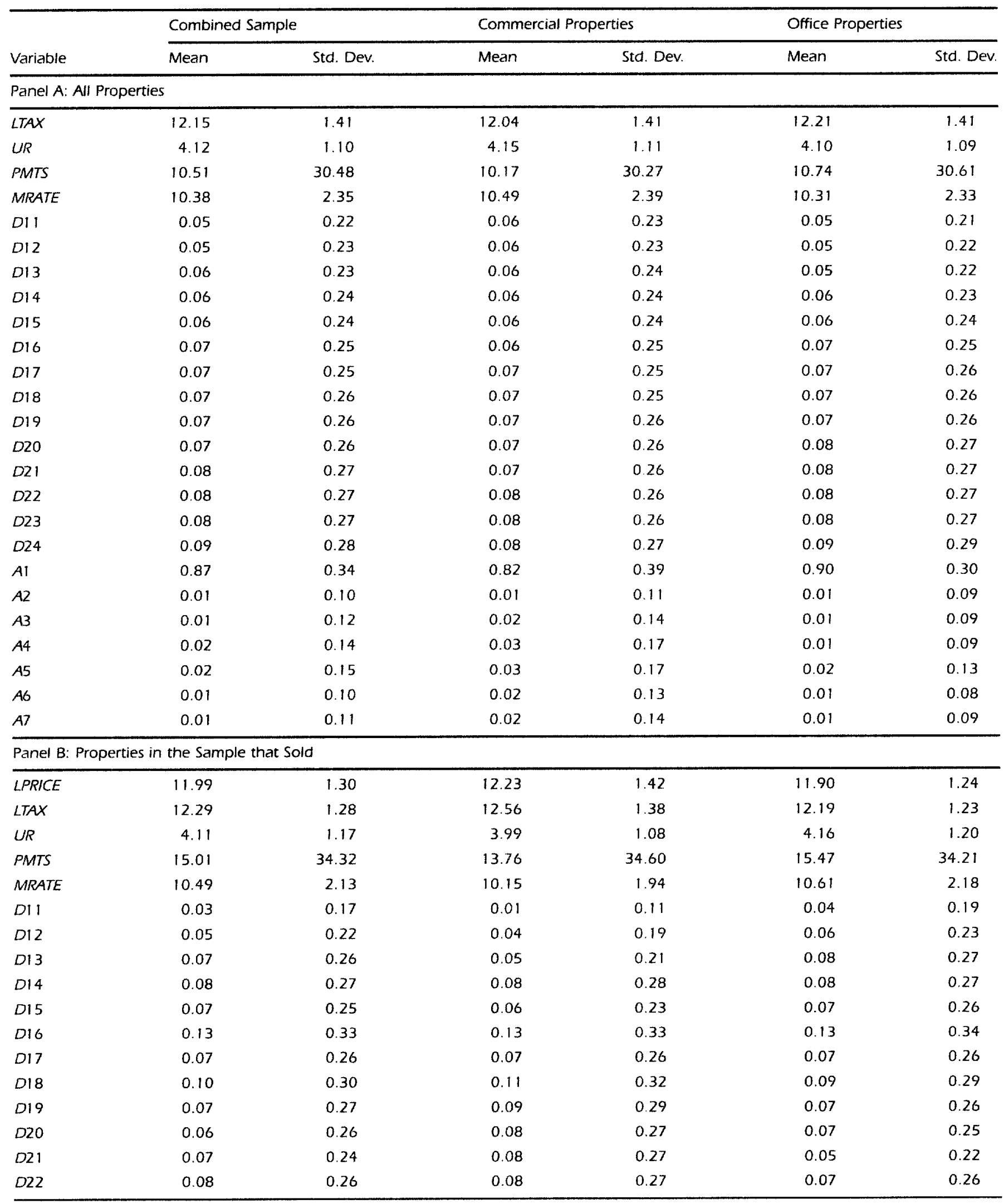


Exhibit 1 (continued)

Means and Standard Deviations

\begin{tabular}{|c|c|c|c|c|c|c|}
\hline \multirow[b]{2}{*}{ Variable } & \multicolumn{2}{|c|}{ Combined Sample } & \multicolumn{2}{|c|}{ Commercial Properties } & \multicolumn{2}{|c|}{ Office Properties } \\
\hline & Mean & Std. Dev. & Mean & Std. Dev. & Mean & Std. Dev. \\
\hline \multicolumn{7}{|c|}{ Panel B: Properties in the Sample that Sold (continued) } \\
\hline$D 23$ & 0.01 & 0.27 & 0.09 & 0.29 & 0.08 & 0.26 \\
\hline$D 24$ & 0.87 & 0.12 & 0.01 & 0.12 & 0.01 & 0.12 \\
\hline$A 1$ & 0.01 & 0.33 & 0.81 & 0.39 & 0.90 & 0.31 \\
\hline$A 2$ & 0.02 & 0.08 & 0.01 & 0.11 & 0.00 & 0.07 \\
\hline A3 & 0.02 & 0.13 & 0.03 & 0.17 & 0.01 & 0.10 \\
\hline A4 & 0.02 & 0.14 & 0.05 & 0.22 & 0.01 & 0.08 \\
\hline A5 & 0.02 & 0.15 & 0.03 & 0.16 & 0.02 & 0.15 \\
\hline A6 & 0.01 & 0.10 & 0.02 & 0.13 & 0.01 & 0.08 \\
\hline A7 & 0.01 & 0.08 & 0.01 & 0.01 & $<0.01$ & 0.07 \\
\hline
\end{tabular}

models. The presence of heteroskedasticity is noted by the large $L M$ statistic (Breusch and Pagan, 1979); therefore, the probit results are corrected for heteroskedasticity. ${ }^{6}$

The $L T A X$ variable is positive and statistically significant for the combined sample; however, a closer look suggests this relation is driven by the commercial property sample. The marginal effects column shows that a $1 \%$ increase in the tax value increases the probability of sale by $0.5 \%$. Office properties show no statistically significant relationship between $L T A X$ and the probability of sale. As anticipated, the unemployment rate variable has a negative sign in all three samples; however, the office probit equation is not statistically significant at the .05 level. For the commercial sample, a $1 \%$ increase in the unemployment rate reduces the probability of sale by about $0.3 \%$, which is large considering only about $2.3 \%$ of the sample actually is sold. Likewise, the PMTS variable has the expected positive sign, and it is statistically significant in all three samples. However, the marginal effect indicates the economic impact of PMTS on the probability of sale is relatively small.

The MRATE variable is positive and statistically significant in the combined sample, but the separate commercial and office probit equations show disparate findings. In particular, MRATE is positive and strongly significant for offices, but for commercial properties, it is negative and statisti- cally insignificant. We would not suggest that higher rates increase sales, but our objective here is not so much with the individual determinants of a sale as with the overall question of whether a sale influences price in the second equation. An analogy might be drawn to the problem of multicollinearity in classical regression. A wrong sign on an individual coefficient is not necessarily indicative of an equation that forecasts badly. Here we are mainly concerned with using the predicted probabilities from the probit model to correct the price equation for selection bias.

The majority of the municipal-area dummy variables are statistically insignificant with the exception of two areas for commercial properties and one area for office properties. The Cornelius and Pineville municipalities were associated with a $1.6 \%$ increased probability of sale for commercial properties, while the Mint Hill municipality was had a $2.6 \%$ reduction in the probability of sale for office properties.

The sample selection price regressions are presented in Exhibit $3 .^{7}$ All three regressions show a statistically significant $F$-value and high adjusted $R^{2}$ exceeding $81 \%$. The estimated $\lambda$ coefficient provides a direct test of sample selection bias; for the combined sample, we find no evidence of sample selection bias. However, the findings are mixed. While the commercial property sample has a statistically insignificant $t$-value for the $\lambda$ coefficient, 


\section{Exhibit 2}

\section{Probit Selection Equations}

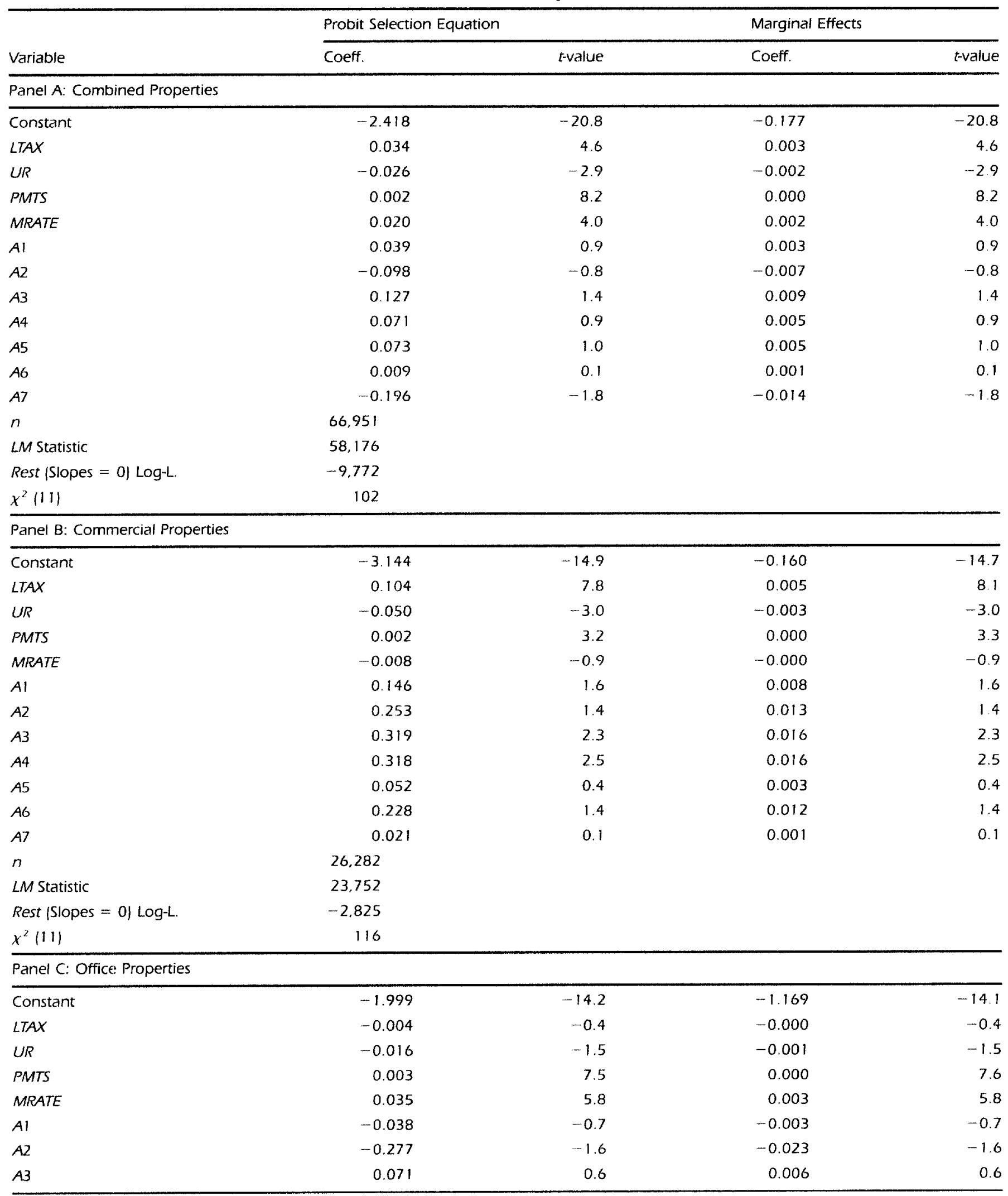


Exhibit 2 (continued)

Probit Selection Equations

\begin{tabular}{lcrr}
\hline & Probit Selection Equation & & Marginal Effects \\
\hline Variable & \multicolumn{1}{l}{ Coeff. } & t-value & Coeff. \\
\hline Panel C: Office Properties (continued) & & & $t$-value \\
\hline A4 & -0.125 & -0.9 & -0.011 \\
A5 & 0.106 & 1.1 & 0.009 \\
A6 & 0.018 & 0.1 & 0.002 \\
A7 & -0.311 & -1.9 & 0.1 \\
$n$ & 40.669 & & -1.9 \\
LM Statistic & 34,494 & & \\
Rest (Slopes $=0$ ) Log-L. & $-6,815$ & & \\
$x^{2}$ (1) & 90 & & \\
\hline
\end{tabular}

Exhibit 3

Commercial and Office Price Regressions

\begin{tabular}{|c|c|c|c|c|c|c|}
\hline \multirow[b]{2}{*}{ Variable } & \multicolumn{2}{|c|}{ Combined Properties } & \multicolumn{2}{|c|}{ Commercial Properties } & \multicolumn{2}{|c|}{ Office Properties } \\
\hline & Coeff. & $t$-value & Coeff. & tvalue & Coeff. & $t$-value \\
\hline Constant & 0.257 & 1.3 & -2.329 & -1.3 & -1.955 & -17 \\
\hline LTAX & 0.875 & 50.9 & 0.959 & 19.0 & 0.864 & 63.4 \\
\hline$D 11$ & 0.497 & 4.7 & 0.296 & 1.1 & 0.572 & 4.9 \\
\hline$D 12$ & 0.275 & 2.7 & -0.248 & -1.1 & 0.508 & 4.2 \\
\hline$D 13$ & 0.515 & 5.4 & 0.335 & 1.5 & 0.619 & 5.6 \\
\hline DI 4 & 0.563 & 6.0 & 0.452 & 2.2 & 0.640 & 6.2 \\
\hline 015 & 0.790 & 8.0 & 0.845 & 3.8 & 0.839 & 7.9 \\
\hline$D 16$ & 0.865 & 7.0 & 0.919 & 4.0 & 1.071 & 7.8 \\
\hline$D 17$ & 0.872 & 9.3 & 0.924 & 4.2 & 0.829 & 7.8 \\
\hline$D 18$ & 0.991 & 10.9 & 0.999 & 4.7 & 0.937 & 8.7 \\
\hline$D 19$ & 1.014 & 10.3 & 0.999 & 4.5 & 1.095 & 10.3 \\
\hline$D 20$ & 1.019 & 10.1 & 1.106 & 5.2 & 0.839 & 6.6 \\
\hline$D 21$ & 0.997 & 9.4 & 0.920 & 4.4 & 0.877 & 6.8 \\
\hline 022 & 0.986 & 10.4 & 1.015 & 4.8 & 0.901 & 8.0 \\
\hline 023 & 0.948 & 9.8 & 0.961 & 4.5 & 0.831 & 6.7 \\
\hline 024 & 1.162 & 9.1 & 1.548 & 5.4 & 1.026 & 7.2 \\
\hline$\lambda$ & 0.076 & 0.2 & 0.723 & 1.5 & 1.168 & 2.1 \\
\hline$n$ & \multicolumn{2}{|c|}{2,228} & \multicolumn{2}{|c|}{606} & \multicolumn{2}{|c|}{1.622} \\
\hline$F$-value & \multicolumn{2}{|c|}{643.35} & \multicolumn{2}{|c|}{182.94} & \multicolumn{2}{|c|}{458.10} \\
\hline$R^{2}-a d j$ & \multicolumn{2}{|c|}{0.822} & \multicolumn{2}{|c|}{0.828} & \multicolumn{2}{|c|}{0.819} \\
\hline$\sigma_{k}$ & \multicolumn{2}{|c|}{0.546} & \multicolumn{2}{|c|}{0.580} & \multicolumn{2}{|c|}{0.526} \\
\hline$\hat{\rho}$ & \multicolumn{2}{|c|}{0.019} & \multicolumn{2}{|c|}{0.656} & \multicolumn{2}{|c|}{0.934} \\
\hline
\end{tabular}




\section{Exhibit 4}

Commercial and Office Indexes

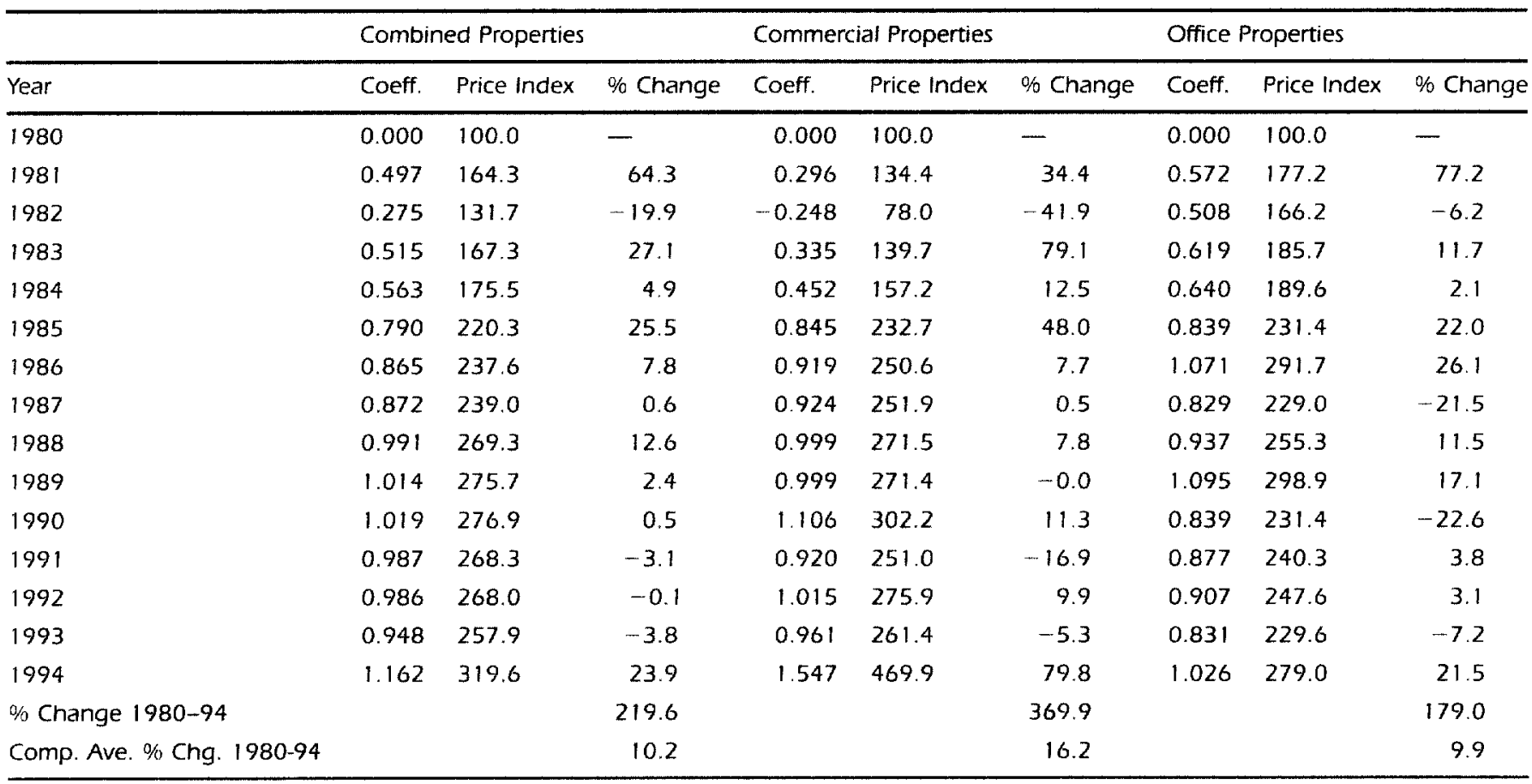

the office sample shows the $t$-value of 2.1 for the $\lambda$ coefficient, suggesting the rejection of the null hypothesis of no sample selection bias. The positive $\lambda$ coefficient indicates higher prices for equivalent office properties that sold versus those that did not sell. ${ }^{8}$ In the office regression, the $\hat{\rho}=.9335$ suggests a strong positive correlation between the error term from the probit equation with that of the regression equation. Note that the mean of the LTAX variable for office properties in Exhibit 1 is $1.2 .21(\$ 200,787)$, which is more than that of the office properties that sold of $12.189(\$ 196,614)$. Accordingly, the mean of the office properties that sold would have been lower if it were not for the selection process that occurs when properties are offered for sale and sold.

The dummy coefficients of $D 11$ through $D 24$, measure the average annual percentage change in price. With the exception of only three dummy variables in the commercial property sample, all of these variables are statistically significant.

Prices indexes are constructed in Exhibit 4 using the dummy variables. Over the fourteen year time period starting in 1980 , the combined sample had an average arithmetic appreciation rate of approximately $10.2 \%$ per year. The commercial property sample had a much larger average appreciation rate of $16.2 \%$ per year. The office property sample, by contrast, had an average appreciation rate of 9.9\%. The largest gains in the average value of commercial property occurred in 1983 and 1994, as the economy was entering an economic expansion. The biggest declines were recorded in 1982 and 1991 , when the economy was mired in recession. For office properties, large gains were made in $1981,1985,1986$ and 1994. Substantial losses were sustained in 1987 and 1990.

\section{Conclusion}

This study develops a nonresidential, constantquality price index, based on the assessed-value approach and adjusts for the possibility for sample selection bias. The sample consists of a large sample of commercial and office properties located in Charlotte, N.C. for 1981-1994. The procedure used to adjust for sample selection bias employs a two- 
step procedure developed by Heckman (1979). In the first stage, a probit equation is estimated by maximum likelihood to obtain estimates of the probability of sale. In the second stage, least squares regression is used to obtain consistent estimates of the price index, which are adjusted for the likelihood of sale.

Statistical tests for sample selection bias suggest that sample selection bias is present in the office sample, but not in the commercial property sample. For office properties, the selection process is such that higher prices prevail for equivalent office properties that sell relative to those that do not sell. This result contrasts to that reported by WMG who found no selectivity bias in their sample of office properties.

Estimated real estate price indexes for the Charlotte area indicate an annual rate of price appreciation of $16.2 \%$ for commercial properties and $9.9 \%$ for office properties. The application of the AV methodology to other regions and other time periods presents an interesting research opportunity. Because the data are relatively easy to obtain from local taxing authorities, it is possible to envision the construction of non-residential price indexes for a number of different MSAs, facilitating the analysis of price trends across the country.

\section{Notes}

1. Studies of price trends emanate from early works by Wyngarden (1927) and Wenzlick (1952). From these early works developed the repeat sales method (Bailey, Muth and Nourse (1963). The hedonic regression approach (Court, 1939; and Griliches, 1961), originally developed to track automotive prices, is now employed extensively in intertemporal studies of house prices.

2. The Volume 6, Number 3 (1995) issue of the Journal of Housing Research also was devoted entirely to the topic of house price indices.

3. $\mathrm{C} \& \mathrm{G}$ compare the AV method to the repeat sales (RS) methods used by Case and Shiller (1989) and others. C\&G (p. 305) show that "the AV and RS methods give substantially the same estimates of price trends over a five- to seven-year period."

4. Jud and Epley (1991) have shown that during the 1980s regional differences in mortgage rates were largely eliminated.

5. LIMDEP 6.0 was used for all the computations.

6. This correction changes the standard errors but not the coefficient values.
7. The price equations were estimated using the White (1980) correction for heteroskedasticity.

8. See, Dolton and Makepeace (1987).

\section{References}

Abraham, J. M., and W. S. Schauman, New Evidence on House Prices from Freddie Mac Repeat Sales, Journal of the American Real Estate and Urban Economics Association, 1991, 19:3, 333-52.

Bailey, M. J., R. F. Muth and H. O. Nourse, A Regression Method for Real Estate Price Index Construction, Journal of the American Statistical Association, 1963, 58, 933-42.

Case, B., H. O. Pollakowski and S. M. Wachter, On Choosing Among House Price Index Methodologies, Journal of the American Real Estate and Urban Economics Association, 1991, 19: 3, 286-307.

Case, B., and J. M. Quigley, Dynamics of Real Estate Prices, Review of Economics and Statistics, 1991, 73:3, 50-58.

Case, K. E., and R. J. Shiller, The Efficiency of the Market for Single-Family Homes, American Economic Review, 1989, 79:1, 125-137.

Clapp, J. M. and C. Giaccotto, Estimating Price Indices for Residential Property: A Comparison of Repeat Sales and Assessed Value Methods, Journal of the American Statistical Association, 1992, 87:418, 300-06.

Court, A. T., Hedonic Prices Indexes with Automotive Examples, in The Dynamics of Automobile Demand, New York: General Motors Corporation, 1939, 99-117.

Dolton, P. J. and G. H. Makepeace, Interpreting Sample Selection Effects, Economics Letters, 1987, 24, 373-79.

Follain, J. R. and C. A. Calhoun, Constructing Indices of the Price of Multifamily Properties Using the 1991 Survey of Residential Finance, Journal of Real Estate Finance and Economics, 1997, 14:2, 235-55.

Gatzlaff, D. H. and D. R. Haurin, Sample Selection Bias and Repeat-Sales Index Estimates, Journal of Real Estate Finance and Economics, 1997, 14:1, 33-50.

Gatzlaff, D. H. and D. R. Haurin, Sample Selection Biases in Local House Value Indexes, Journal of Urban Economics, 1998, $43: 2,199-222$.

Greene, W. H., Econometric Analysis, New York: MacMillan Co., 1993.

Griliches, Z., Hedonic Price Indexes for Automobiles: An Econometric Analysis of Quality Change, in The Price Statistics of the Federal Government, General Series, No. 73, 137-196. New York: National Bureau of Economic Research, 1961.

Guttery, R. S. and C. F. Sirmans, Creating a Constant-Quality Index for Small, Multifamily Rental Housing, Journal of Real Estate Research, 1995, 10:5, 557-68.

Guttery, R. S. and C. F. Sirmans, Aggregation Bias in Price Indices for Multi-Family Rental Properties, Journal of Real Estate Research, 1998, 15:3, 309-25.

Haurin, D. R. and P. H. Hendershott, Housing Price Indexes: Issues and Results, The Journal of the American Real estate and Urban Economics Association, 1991, 19:3, 259-69. 
Heckman, J. Sample Selection Bias as a Specification Error Econometrica, 1979, 47:1, 153-61.

Hill, R. C., J. R. Knight and C. F. Sirmans, Estimating Capital Asset Pricing Indexes, Review of Economics and Statistics, 1997, 79:2, 226-33

Jud, G. D. and D. R. Epley, Regional Differences in Mortgage Rates: An Updated Examination, Journal of Housing Economics, 1991, 1:2, 127-39.

Jud, G. D. and T. G. Seaks, Sample Selection Bias in Estimating Housing Sales Prices, Journal of Real Estate Research, 1994, 9:3, 289-98.

Knight, J. R., J. Dombrow and C. F. Sirmans, A Varying Parameters Approach to Constructing House Price Indexes, Real Estate Economics, 1995, 23:2, 187-205.

Mark, J. H. and M. A. Goldberg, Alternative Housing Price Indexes: An Evaluation, Journal of the American Real Estate and Urban Economics Association, 1984, 12:1, 30-49.
Webb, R. B., M. Miles and D. Guilkey, Transactions-Driven Commercial Real Estate Returns: The Panacea to Asset Allocation Models? Journal of the American Real Estate and Urban Economics Association, 1992, 20:1, 325-57.

Wenzlick, R., Trends in Selling Prices, The Real Estate Analyst, $1952,21,544-545$.

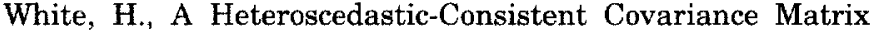
Estimator and a Direct Test for Heteroscedasticity, Econometrica, 1980, 48:4, 817-838.

Wyngarden, H., An Index of Local Real Estate Prices, Michigan Business Studies 1, Ann Arbor, University of Michigan, 1927.

The authors are indebted to two anonymous referees and to Youguo Liang for their helpful comments and suggestions on an earlier draft of this article. 